\title{
Source model for generating strong ground motions during the 2011 off the Pacific coast of Tohoku Earthquake
}

\author{
Susumu Kurahashi and Kojiro Irikura \\ Disaster Prevention Research Center, Aichi Institute of Technology, 1247 Yachigusa, Yakusa, Toyota, Aichi 470-0392, Japan
}

(Received April 18, 2011; Revised June 20, 2011; Accepted June 23, 2011; Online published September 27, 2011)

\begin{abstract}
A source model for generating strong ground motions during the 2011 off the Pacific coast of Tohoku Earthquake $\left(M_{\mathrm{w}} 9.0\right)$ is estimated from a comparison of the observed records of the mainshock and synthetic motions, based on the characterized source model using the empirical Green's function method. The characterized source model consists of several strong-motion-generation-areas (SMGAs) with high slip velocity superimposed upon the larger rupture area of the earthquake. The final source model has five SMGAs with different sizes, using a trial and error approach. SMGA 1 is located west of the hypocenter in the source region of Southern Sanriku-oki and SMGA 2 in that of the Middle Sanriku-oki, north of the hypocenter. SMGA 3, SMGA 4, and SMGA 5 are located near the down-dip edge of the mainshock source fault, ranging from offshore Miyagi to offshore Ibaraki prefectures. The delay times from the origin time are $15.6 \mathrm{sec}$ at SMGA 1, $66.4 \mathrm{sec}$ at SMGA 2, 68.4 sec at SMGA 3, $109.7 \mathrm{sec}$ at SMGA 4 and $118.2 \mathrm{sec}$ at SMGA 5. The probabilities of earthquake occurrence in these source regions including the five SMGAs have been estimated by the Earthquake Research Committee at less than $7 \%$ to $99 \%$ with magnitude about 6.9 to 7.5 , individually, except the source region of the Middle Sanriku-oki.
\end{abstract}

Key words: The 2011 off the Pacific coast of Tohoku Earthquake, strong-motion-generation-areas, the empirical Green's function method.

\section{Introduction}

The 11 March 2011 giant earthquake with $M_{\mathrm{w}} 9.0$ occurred off the Pacific coast of Tohoku and is the largest historical earthquake to strike in or near Japan. This event had a maximum seismic intensity of 7 on the Japanese scale (corresponding to greater than 10 on the Modified Mercalli scale) at a site in Kurihara about $50 \mathrm{~km}$ north of Sendai. The huge tsunami generated by this earthquake struck the eastcoast along Tohoku, resulting in more than 23,000 people being killed or missing. The tsunami waves were also responsible for severe accidents at the nuclear reactors in the Fukushima Daiichi Nuclear Power Plant, which further intensified the scope of the disaster.

This event occurred on the boundary between the Pacific and the continental plates. The focal mechanism showed a reverse fault with a compression axis in a WNW-ESE direction. The source extent is approximately $450 \mathrm{~km}$ in length and approximately $200 \mathrm{~km}$ in width and that the maximum slip is about $30 \mathrm{~m}$, as derived from various analyses of teleseismic data, crustal movement and tsunami data (ERC, 2011). As shown in Fig. 1, the rupture area covers the regions of Middle-Sanriku-oki, Southern-Sanriku-oki, Miyagi-oki, Fukushima-oki and Ibaraki-oki, in which probabilities of earthquake occurrence for the period of 2011 to 2040 have been estimated by the Earthquake Research

Copyright (C) The Society of Geomagnetism and Earth, Planetary and Space Sciences (SGEPSS); The Seismological Society of Japan; The Volcanological Society of Japan; The Geodetic Society of Japan; The Japanese Society for Planetary Sciences; TERRAPUB.

doi: $10.5047 /$ eps.2011.06.044
Committee (ERC), $M=7.6-7.8$ at $80 \%$ for the SouthernSanriku-oki, $M=7.4-7.6$ at $99 \%$ for the Miyagi-oki, $M=7.3-7.5$ at less than $7 \%$ for the Fukushima-oki and $M=6.7-7.2$ at more than $90 \%$ for the Ibaraki-oki, respectively, except the Middle Sanriku-oki.

Slip distribution models have been inverted using teleseismic, geodetic, and tsunami data by many researchers (e.g., Fujii and Satake, 2011; Ide et al., 2011; Iinuma et al., 2011; Yagi and Nishimura, 2011; Yamanaka, 2011). However, these initial modeling results exhibit significant variability, with notably dissimilar features. For example, some of the models have the main slip distribution west of the hypocenter, while others locate it east of the hypocenter towards the Japan Trench zone. The slip distributions from the tsunami data show large slip near the Trench zone.

Strong motion data in the near-source region provide more detailed information about the shorter period rupture process during the earthquakes. In our study, we estimate a source model for generating strong ground motions from this earthquake by comparing the observed records from the mainshock with synthesized motions based on a characterized source model and the empirical Green's function method. The characterized source model consists in several strong-motion-generation-areas (SMGAs) with large slip velocity or high stress drop, distributed across the entire rupture area of the earthquake. The goal of this study is to determine those areas in the regions from off-shore Iwate to off-shore Ibaraki prefectures that contributed most significantly to the generation of strong ground motion during this earthquake. 


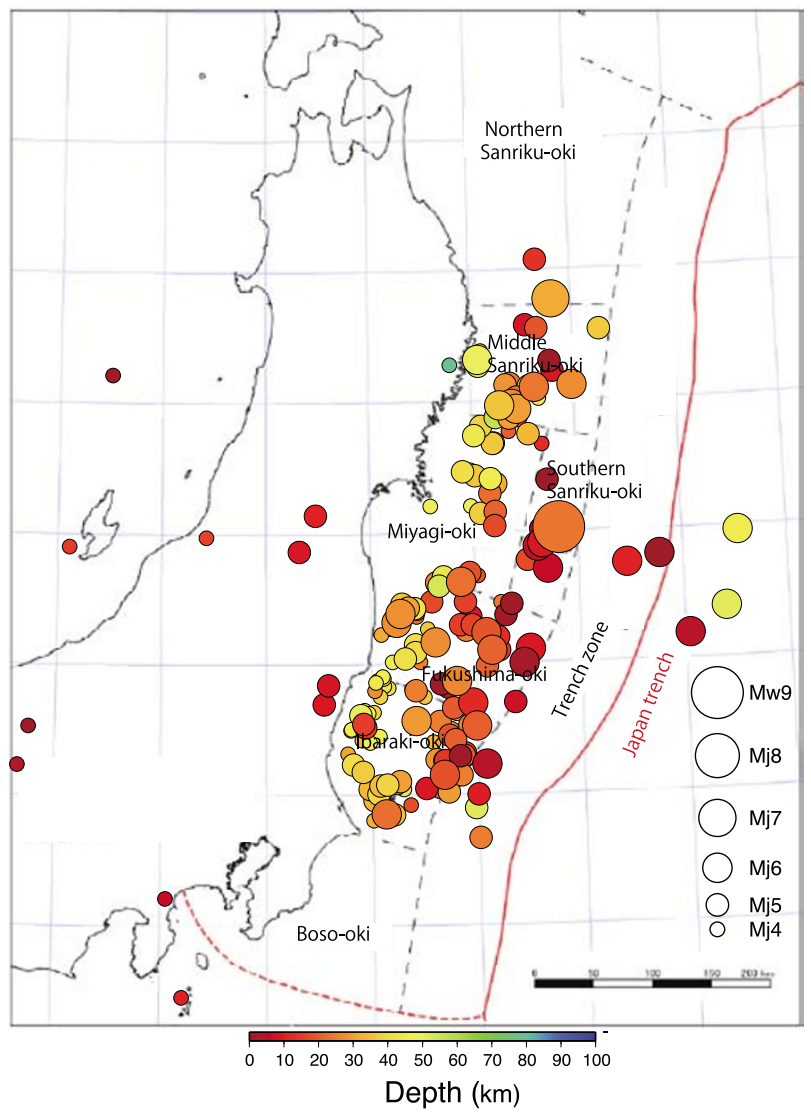

Fig. 1. Distribution of aftershocks more than JMA magnitude $\left(M_{\mathrm{j}}\right) 4$ for a day after the mainshock. The divided regions in the background map show the source regions for estimating probabilities of earthquake occurrences by the Earthquake Research Committee (2009), separately. The epicenter of the mainshock is shown as $M_{\mathrm{W}} 9.0$ by the largest circle.
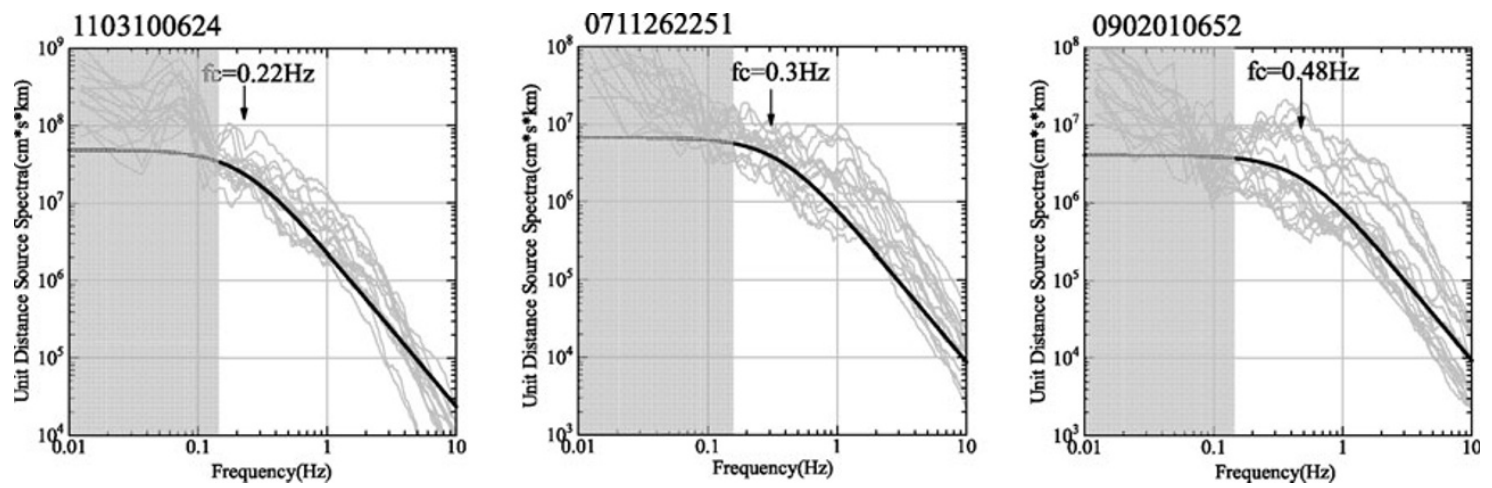

Fig. 2. Displacement spectra estimated from ground motion records at underground stations on rock from three small events (Event A, Event B, and Event C) used as the empirical Green's functions. The shadow areas at low-frequencies lower than $0.15 \mathrm{~Hz}$ show unreliable frequency ranges that are not used for the simulation.

\section{Ground Motion Data}

Strong ground motions at more than 1,000 stations of KNET and KiK-net belonging to National Research Institute for Earth Science and Disaster Prevention (NIED) and other organizations were observed throughout Japan, including near-source areas along the Pacific coast of Tohoku. Inland areas from Miyagi to Tochigi experienced very large highfrequency ground motions with peak accelerations of more than 1000 gals occurring at 20 stations (NIED, 2011). The strongest peak accelerations of 2933 and 2019 gals (composite of three components) were measured in Miyagi prefecture at the K-NET stations MYG004 and MYG012, re- spectively, at the shortest distances of about 70 to $80 \mathrm{~km}$ from the assumed source fault.

In our analysis, the strong motion data at 14 underground stations of KiK-net in near-distance regions ranging from Iwate to Ibaraki prefectures are used to constrain the source modeling (Fig. 4). To simulate strong ground motions from SMGAs using the empirical Green's function method (Irikura, 1986), ground motion records from small events near the SMGAs are needed. From preliminary analysis, we identified five potential SMGAs, three of which appear to be close to each other, as discussed in the next section. Therefore, we selected three small events (Event A, Event B, and 
Table 1. The source parameters of the mainshock and Small Events A, B, and C.

\begin{tabular}{cccccccc}
\hline & Origin time & $\begin{array}{c}\text { Latitude } \\
(\mathrm{deg})\end{array}$ & $\begin{array}{c}\text { Longitude } \\
(\mathrm{deg})\end{array}$ & $M_{\mathrm{w}}$ & $\begin{array}{c}\text { Strike } \\
(\mathrm{deg})\end{array}$ & $\begin{array}{c}\text { Dip } \\
(\mathrm{deg})\end{array}$ & $\begin{array}{c}\text { Rake } \\
(\mathrm{deg})\end{array}$ \\
\hline Mainshock & $2011 / 3 / 1114: 46$ & 38.103 & 142.86 & 9.0 & $24 / 193$ & $81 / 10$ & $92 / 79$ \\
\hline
\end{tabular}

\begin{tabular}{lccccccccccc}
\hline & Origin time & $\begin{array}{c}\text { Latitude } \\
(\mathrm{deg})\end{array}$ & $\begin{array}{c}\text { Longitude } \\
(\mathrm{deg})\end{array}$ & $M_{\mathrm{w}}$ & $\begin{array}{c}\text { Strike } \\
(\mathrm{deg})\end{array}$ & $\begin{array}{c}\text { Dip } \\
(\mathrm{deg})\end{array}$ & $\begin{array}{c}\text { Rake } \\
(\mathrm{deg})\end{array}$ & $\begin{array}{c}M_{\mathrm{o}} \\
(\mathrm{N} \mathrm{m})\end{array}$ & $\begin{array}{c}\text { Coner frequency } \\
(\mathrm{Hz})\end{array}$ & $\begin{array}{c}\text { Stress drop } \\
(\mathrm{MPa})\end{array}$ & $\begin{array}{c}\text { Area } \\
\left.(\mathrm{km})^{2}\right)\end{array}$ \\
\hline Event A & $2011 / 3 / 106: 24$ & 38.172 & 143.045 & 6.5 & $22 / 213$ & $68 / 23$ & $85 / 101$ & $5.51 \mathrm{E}+18$ & 0.22 & 11.8 & 108.9 \\
Event B & $2007 / 11 / 2622: 51$ & 37.304 & 141.757 & 5.9 & $24 / 217$ & $71 / 20$ & $86 / 102$ & $7.66 \mathrm{E}+17$ & 0.3 & 4.1 & 58.5 \\
Event C & $2009 / 2 / 16: 52$ & 36.717 & 141.279 & 5.7 & $25 / 232$ & $76 / 15$ & $83 / 116$ & $4.65 \mathrm{E}+17$ & 0.48 & 10.4 & 22.9 \\
\hline
\end{tabular}
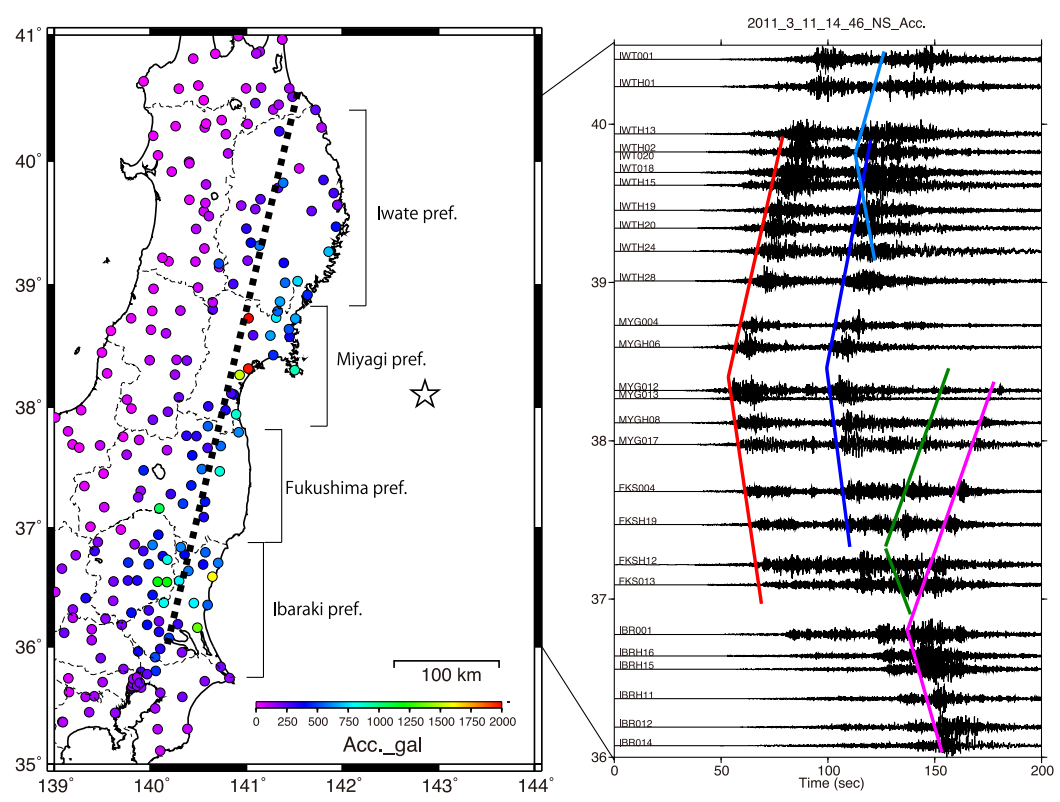

Fig. 3. Left: Map showing the location of observed stations. Right: acceleration seismograms at stations along a line from north to south. The colored thin solid lines indicate the travel times of $S$ waves generated from five strong-motion-generation-areas. Red, sky-blue, blue, green and pink are for the $S$ waves propagating from SMGA 1, SMGA 2, SMGA 3, SMGA 4 and SMGA 5 to the stations, respectively.

Event C) to use for the empirical Green's function analysis. Ground motions from the three small events were recorded at the same stations as the mainshock. The source parameters of the small events, including source areas and stress drops, are estimated from the seismic moment reported by F-net and the corner frequency of the source spectrum from each small event, as shown in Fig. 2. The source parameters of the mainshock and the small events are shown in Table 1 . In this study, the observed records used as the empirical Green's functions are band-pass-filtered from $0.15 \mathrm{~Hz}$ to $10 \mathrm{~Hz}$, considering the reliable frequency range of the observed records from the small events.

\section{Source Model for Generating Strong Ground Motions}

3.1 Locations of strong motion generation areas

Based on the aftershock distribution in the first 24 hours and the CMT solution by the Japan Meteorological Agency (JMA), we define the source fault as roughly $450 \mathrm{~km}$ long and $200 \mathrm{~km}$ wide with strike of $193^{\circ}$ and dip $10^{\circ}$. The hypocenter is at $38.1033 \mathrm{~N}, 142.86 \mathrm{E}$, and $23.7 \mathrm{~km}$ deep by JMA in Fig. 1.

The locations of the SMGAs are constrained using the back-propagation method of Kurahashi and Irikura (2010).
The acceleration records at stations along a line from north to south are arranged with the same time and amplitude scale in Fig. 3. In the aligned records, several isolated wave-packets are found arriving from different origins on the source fault. Such origins are considered to be the strong motion generation areas (SGMAs).

We identified five wave-packets in the observed seismograms, which originate from five SMGAs on the source fault. The onsets of the wave-packets are found to propagate with a certain velocity, as shown in Fig. 3. We can estimate the locations of the SMGAs based on the onset times of the wave-packets at many stations. The origin of each wave-packet, which is the starting point of each SMGA, is theoretically determined on the source fault from the arrival times at more than three stations by the back-propagation method, taking the coordinates $(x, y$, and $z)$ and rupture velocity $V_{\mathrm{r}}$ as variables and assuming unbounded media with constant $S$ wave velocity $V_{\text {s }}$ (Kurahashi and Irikura, 2010). However, for the Tohoku earthquake, strong motion data exist only on the west side of the source fault. Therefore, the initiation of each SMGA cannot be isolated at a point, but rather it is blurred along an area about $20 \mathrm{~km}$ in length, due to the poor spatial coverage of the observation sites.

After estimating the approximate location of each SMGA 
Table 2. The source parameters of each SMGA.

\begin{tabular}{lccccc}
\hline & $\begin{array}{c}L \\
(\mathrm{~km})\end{array}$ & $\begin{array}{c}W \\
(\mathrm{~km})\end{array}$ & $\begin{array}{c}M_{\mathrm{o}} \\
(\mathrm{N} \mathrm{m})\end{array}$ & $\begin{array}{c}\text { Stress drop } \\
(\mathrm{MPa})\end{array}$ & $\begin{array}{c}\text { Delay time from origin time } \\
(\mathrm{sec})\end{array}$ \\
\hline SMGA 1 & 62.40 & 41.60 & $2.31 \mathrm{E}+21$ & 41.3 & 15.64 \\
SMGA 2 & 41.60 & 41.60 & $7.05 \mathrm{E}+20$ & 23.6 & 66.42 \\
SMGA 3 & 93.60 & 52.00 & $4.34 \mathrm{E}+21$ & 29.5 & 68.41 \\
SMGA 4 & 38.50 & 38.50 & $3.83 \mathrm{E}+20$ & 16.4 & 109.71 \\
SMGA 5 & 33.60 & 33.60 & $3.99 \mathrm{E}+20$ & 26.0 & 118.17 \\
\hline
\end{tabular}

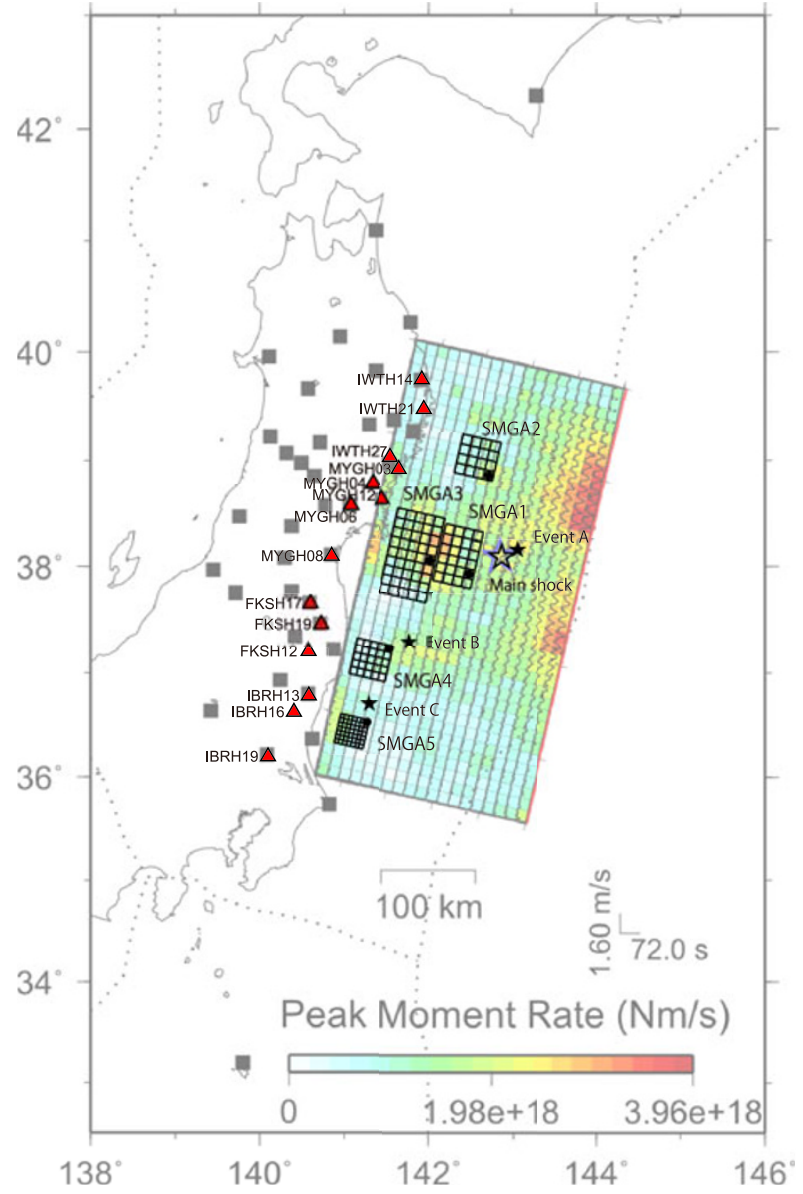

Fig. 4. Source model consisting of five SMGAs. The five SMGAs are superposed on the distribution of peak moment-rate inverted using strong motions data by Yoshida et al. (2011). The initiation point at each SMGA is roughly estimated by the back-propagation method. The area, stress drop and initiation point of each SMGA are estimated from the forward modeling, comparing the observed and synthetics ones using the empirical Green's function method. The open star and closed stars show the epicenters of the mainshock and small events A, B, and C, respectively. The small rectangles and closed circles inside them show the SMGAs and their initiation points. The closed red triangles indicate the KiK-net stations used for analysis.

by the back-propagation method, we calculated ground motions from the SMGA assuming its area (length $\times$ width) and initiation point. We then obtained the final solutions for the area and initiation point by comparing the observed seismograms of each wave-packet and the synthetic ones at many stations using a trial and error approach. The fitting function is adopted to minimize the sum of residuals for acceleration envelopes and velocity waveforms between the observed and synthetic ones.

\subsection{Characterized source model and ground motion simulation}

To calculate ground motions from each SMGA, the area of the SMGA is divided into equally-sized square subfaults, the area of which is set to be the same as the small event area. The rise time and rupture velocity inside each SMGA are given to be $W_{\mathrm{s}} / 4 V_{\mathrm{r}}\left(W_{\mathrm{s}}\right.$ : width of the SMGA and $V_{\mathrm{r}}$ : rupture velocity), following empirical relations by Kataoka et al. (2003). The average $S$ wave velocity is given to be $3.5 \mathrm{~km} / \mathrm{s}$ from $T_{\mathrm{s}-\mathrm{p}}$ time versus arrival time at observed stations. The rupture velocities outside the SMGAs are estimated by the back-propagation method. The total ground motion response at each station is calculated by summing the contributions from the SMGAs with the arrival times from the initiation points of the SMGAs to the station.

The small events' records used as empirical Green's functions (EGFs) have to share the propagation-path and site effects as well as the radiation characteristic from the source. Therefore, the records from the small events (closed star marks in Fig. 4) occurring near the SMGAs are adopted as the EGFs. The records from Event $\mathrm{A}$ are used as the EGFs for SMGA 1, SMGA 2 and SMGA 3 because those SMGAs are located close to each other on the preliminary analysis. Those from Event B and Event $\mathrm{C}$ are used for SMGA 4 and SMGA 5 offshore Fukushima prefecture and offshore Ibaragi prefecture, respectively. The source information of the mainshock and the small events for the EGFs are listed in Table 1.

The characterized source model consisting of five SMGAs is obtained by minimizing the fitting function as described in the previous section. The area and initiation of each SMGA are shown in Fig. 4 by a rectangle and closed circle mark, respectively. The source parameters of the final source model, such as the length, width, seismic moment, stress drop and delay time from the origin time of each SMGA are listed in Table 2. The observed and synthetic ground motions at IWTH27, MYGH04, FKSH19 and IBRH19 from the final source model are shown in Fig. 5. Agreement between the observed and synthetic ones is satisfactory at all of stations.

\section{Discussion and Conclusions}

We find that acceleration as well as velocity motions during the 2011 off the Pacific coast of Tohoku Earthquake $\left(M_{\mathrm{w}} 9.0\right)$ are well simulated using a characterized source model consisting of five SMGAs. SMGA 1 is located in the source region of Southern Sanriku-oki west of the hypocenter and SMGA 2 in that of the Middle Sanriku-oki north of the hypocenter. SMGA3 is located in the source region of 
IWTH27
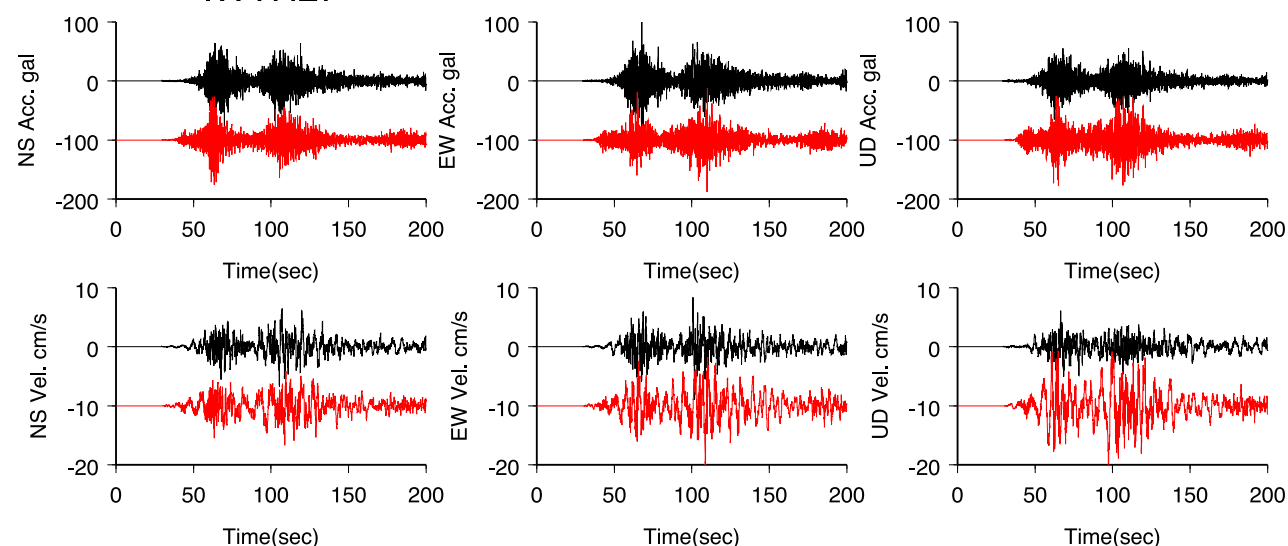

\section{MYGH04}
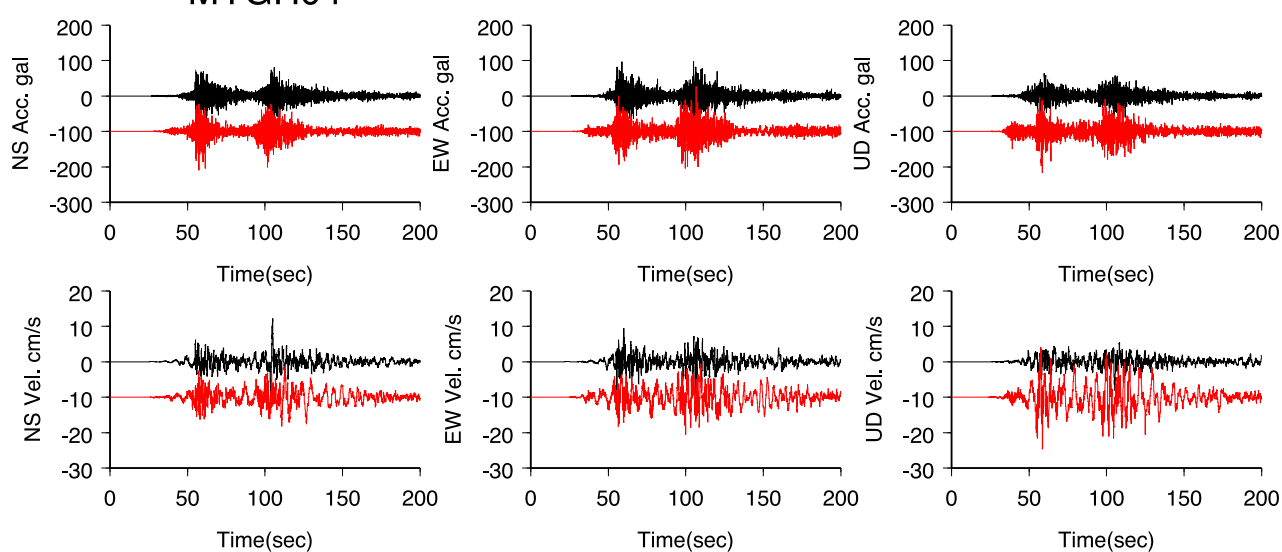

\section{FKSH19}
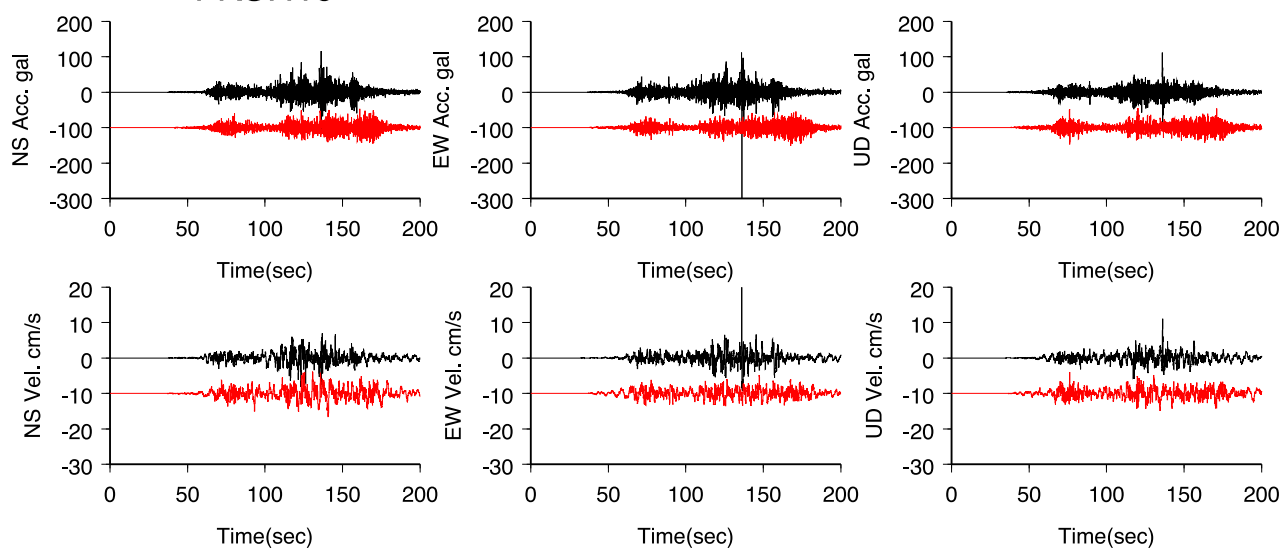

IBRH19
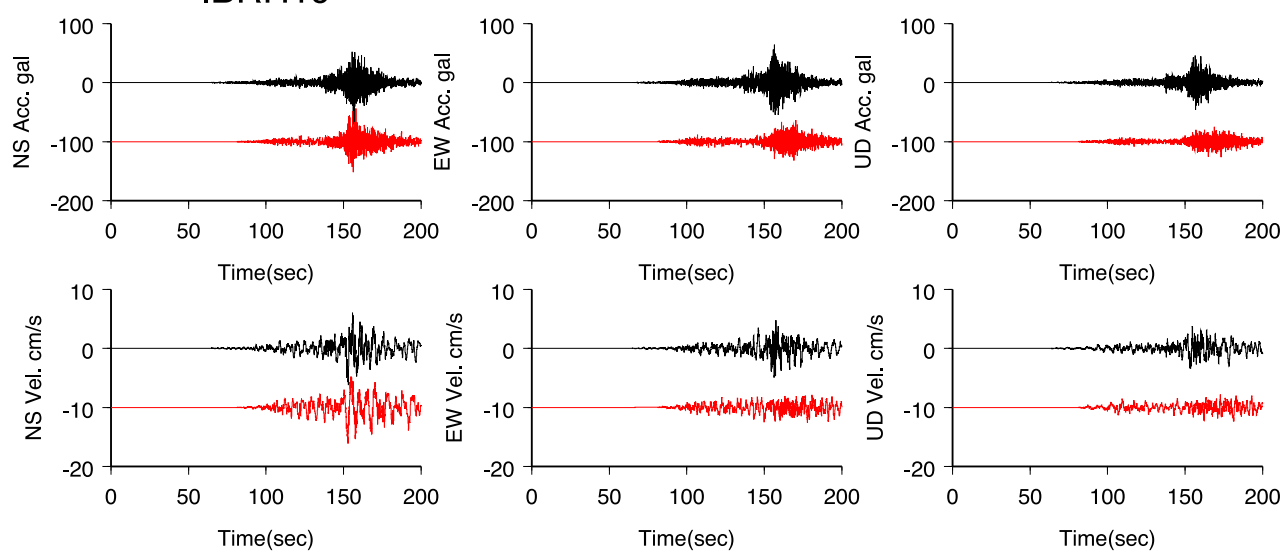

Fig. 5. Comparison of the observed (black lines) and synthetic (red lines) seismograms by the empirical Green's function method at IWTH27, MYGH04, FKSH19 and IBRH19. The acceleration (upper) and velocity (lower) at each station are compared. 
the Miyagi-oki, SMGA 4 is located in that of Fukushimaoki and SMGA 5 is located in that of Ibaraki-oki. SMGA 1, SMGA 2, SMGA 3, SMGA 4, and SMGA 5 initiated to rupture $15.6 \mathrm{sec}, 66.4 \mathrm{sec}, 68.4 \mathrm{sec}, 109.7 \mathrm{sec}$, and 118.2 $\mathrm{sec}$ after the rupture originated at the hypocenter. The probabilities of earthquake occurrence in these source regions including the five SMGAs have been estimated by the ERC at less than $7 \%$ to $99 \%$ with a magnitude of about 6.9 to 7.5 , separately, except the source region of the Middle Sanrikuoki.

For moderate to large magnitude earthquakes $\left(M_{\mathrm{w}}<8\right)$, we usually associate the SMGAs with large slip asperities in the characterized source model. This is based on analyses such as the source characterization by Somerville et al. (1999), which was limited to earthquakes less than about $M_{\mathrm{w}}$ 7.2. However, for great earthquakes of $M_{\mathrm{w}} 9.0$ such as Tohoku, we recognize that the asperities defined by large slip might not always coincide with the higher frequency strong motion generation areas with high slip velocity or high stress drop.

The locations of the SMGAs coincide with large peak moment-rate areas inverted from strong motions data in the low-frequency range $(0.002 \mathrm{~Hz}-0.05 \mathrm{~Hz})$ by Yoshida et al. (2011), particularly along the down-dip edge of the source fault, as shown in Fig. 4. Ground motion simulation in our method shows large amplitude in the forward rupture direction because of the directivity effect but less amplitude in the backward rupture direction. This may explain why the SMGAs have only source areas west to the starting point of each SMGA, which corresponds to the forward rupture direction for the strong motion sites located in Japan. It is certainly possible that the areas of the SMGAs in our analysis might need to be extended more to the east (updip direction), if strong motion data were available in the offshore east of the source fault.

Acknowledgments. We used the wave data provided by the KiKnet of the National Research Institute for Earth Science and Disaster Prevention (NIED). We also used the hypocentral information from the Japan Meteorological Agency and the moment tensor solution from the F-net (NIED). We are very grateful to Dr. Robert Graves and the anonymous reviewer for reviewing the manuscript and providing valuable comments. Some figures were made using the GMT plotting package (Wessel and Smith, 1998).

\section{References}

Earthquake Research Committee, Long-term forecast of earthquakes from Sanriku-oki to Boso-oki (revised), 80 pp., Headquarters for Earthquake Research Promotion, 2009 (in Japanese).

Earthquake Research Committee, The 2011 off the Pacific Coast of Tohoku Earthquake, http://www.jishin.go.jp/main/index-e.html, 2011.

Fujii, Y. and K. Satake, Off Tohoku-Pacific Tsunami on March 11, 2011, http://iisee.kenken.go.jp/staff/fujii/OffTohokuPacific2011/tsunami.html, 2011.

Ide, S., A. Baltay, and G. Beroza, Shallow dynamic overshoot and energetic deep rupture in the $2011 \mathrm{Mw} 9.0$ Tohoku-oki earthquake, Science, doi:10.1126/science.1207020, 2011.

Iinuma, T., M. Ohzono, Y. Ohta, and S. Miura, Coseismic slip distribution of the 2011 Off the Pacific Coast of Tohoku Earthquake estimated based on GPS data, Japan Geoscience Union Meeting 2011, MIS036-P22, 2011.

Irikura, K., Prediction of strong acceleration motions using empirical Green's function, Proc. 7th Japan Earthq. Eng. Symp., 151-156, 1986.

Kataoka, S., K. Takaaki, M. Jun, and T. Keiichi, Study on a Procedure for Formulating Level 2 Earthquake Motion Based on Scenario Earthquakes, Research Report of National Institute for Land and Infrastructure Management, No.15, 2003.

Kurahashi, S. and K. Irikura, Characterized Source Model for Simulating Strong Ground Motions during the 2008 Wenchuan Earthquake, Bull. Seismol. Soc. Am., 100, 2450-2475, 2010.

National Institute of Earth Sciences and Disaster Prevention, 2011 Off the Pacific Coast of Tohoku earthquake, Strong Ground Motion, http://www.k-net.bosai.go.jp/k-net/topics/ TohokuTaiheiyo_20110311/nied_kyoshin2e.pdf, March 13, 2011.

Somerville, P., K. Irikura, R. Graves, S. Sawada, D. Wald, N. Abrahamson, Y Iwasaki, T Kagawa, N. Smith, and A. Kowada, Characterizing crustal earthquake slip models for the prediction of strong ground motion, Seismol. Res. Lett., 70, 59-80, 1999.

Wessel, P. and W. H. F. Smith, New, improved version of Generic Mapping Tools released, Eos, 79, 579, 1998.

Yagi, Y. and N. Nishimura, The Mar 11, 2011 Tohoku-Pacific Coast Earthquake (Ver. 3), http://www.geol.tsukuba.ac.jp/ yagi-y/EQ/Tohoku/

Yamanaka, Y., The March 11, 2011 Off the Pacific Coast of Tohoku earthquake, http://www.seis.nagoya-u.ac.jp/sanchu/Seismo_Note/ 2011/NGY36n.html, 2011.

Yoshida, K., K. Miyakoshi, and K. Irikura, Source process of the 2011 off the Pacific coast of Tohoku Earthquake inferred from waveform inversion with long-period strong-motion records, Earth Planets Space, 63, this issue, 577-582, 2011.

S. Kurahashi (e-mail: susumu@aitech.ac.jp) and K. Irikura 